\title{
Effect of upper respiratory infection on anaesthesia induced atelectasis in paediatric patients
}

\author{
Hye-Mi Lee ${ }^{1}$, Hyo-Jin Byon ${ }^{1}$, Namo Kim² ${ }^{1}$, Stephen J. Gleich², Randall P. Flick ${ }^{2}$ \& \\ Jeong-Rim Lee ${ }^{1 \bowtie}$
}

Upper respiratory tract infection (URI) symptoms are known to increase perioperative respiratory adverse events (PRAEs) in children undergoing general anaesthesia. General anaesthesia per se also induces atelectasis, which may worsen with URIs and yield detrimental outcomes. However, the influence of URI symptoms on anaesthesia-induced atelectasis in children has not been investigated. This study aimed to demonstrate whether current URI symptoms induce aggravation of perioperative atelectasis in children. Overall, 270 children aged 6 months to 6 years undergoing surgery were prospectively recruited. URI severity was scored using a questionnaire and the degree of atelectasis was defined by sonographic findings showing juxtapleural consolidation and B-lines. The correlation between severity of URI and degree of atelectasis was analysed by multiple linear regression. Overall, 256 children were finally analysed. Most children had only one or two mild symptoms of URI, which were not associated with the atelectasis score across the entire cohort. However, PRAE occurrences showed significant correspondence with the URI severity (odds ratio 1.36, 95\% confidence interval 1.10-1.67, $\mathrm{p}=0.004$ ). In conclusion, mild URI symptoms did not exacerbate anaesthesia-induced atelectasis, though the presence and severity of URI were correlated with PRAEs in children. Trial registration: Clinicaltrials.gov (NCT03355547).

A large number of children with upper respiratory tract infection (URI) undergo general anaesthesia for elective or emergency surgery even though URIs are known to increase perioperative adverse respiratory events (PRAEs) $)^{1,2}$. Meanwhile, patients of all ages who undergo general anaesthesia suffer anaesthesia-induced atelectasis which is one of the most pervasive adverse outcomes. In children, the incidence of atelectasis has been shown to range from 60 to $80 \%$.

A series of case studies and one prospective observational study demonstrated that severe pulmonary collapse occurred during anaesthesia in children who had preoperative URI symptoms which were not severe enough to postpone their surgery ${ }^{5-7}$. In addition, transient hypoxia after anaesthesia was observed in children with URI ${ }^{8}$. Accordingly, it is conceivable that anaesthesia-induced atelectasis is possibly aggravated and results in hypoxemia in children with URI ${ }^{6,7,9,10}$. However, no previous study has attempted to demonstrate a direct correlation between the severity of URI and the extent of anaesthesia-induced atelectasis.

Accurate knowledge on the development of atelectasis in children with URI is essential for optimal perioperative anaesthetic care. This prospective observational study aimed to investigate if the severity of URI symptoms is correlated with exacerbation of perioperative atelectasis in children.

\section{Methods}

Trial design and participants. Ethical approval for this study (IRB \#4-2017-0766) was obtained from the Institutional Review Board of Severance Hospital, Seoul, Republic of Korea on 29th September 2017. All study methods were performed in accordance with the relevant guidelines and regulations. Written informed consent was obtained from the parents of all children. The trial was registered prior to patient enrolment at clinicaltrials. gov (NCT03355547, Principal investigator: Jeong-Rim Lee, Date of registration: 28th November 2017).

This study was designed as a prospective observational study of children aged 6 months to 6 years undergoing urologic, lower abdominal, or superficial general surgery under general anaesthesia. This study was conducted

${ }^{1}$ Department of Anaesthesiology and Pain Medicine, Anaesthesia and Pain Research Institute, Yonsei University College of Medicine, 50-1 Yonsei-ro, Seodaemun-gu, Seoul 03722, Republic of Korea. ${ }^{2}$ Department of Anaesthesiology and Perioperative Medicine, Mayo Clinic, 200 1st SW, Rochester, MN 55905, USA. ${ }^{\square}$ email: leejeongrim@gmail.com 


\begin{tabular}{|c|c|c|c|c|}
\hline Symptom & 0 & 1 & 2 & 3 \\
\hline Sneezing & No sneezes & Few short episodes of sneezing & Occasional sneezing & Frequent sneezing \\
\hline Runny Nose & No runny nose & Had to wipe (or blow) nose rarely & Had to wipe (or blow) nose occasionally & Had to wipe (or blow) nose frequently \\
\hline Nasal congestion & No congestion & Slight breathing through nose & $\begin{array}{l}\text { Noisy breathing through nose, has } \\
\text { "nasal" speech, breathes through mouth } \\
\text { sometimes }\end{array}$ & $\begin{array}{l}\text { Breathes through mouth almost all the } \\
\text { time because of nasal congestion, speech } \\
\text { very "nasal" }\end{array}$ \\
\hline Cough & No cough & Few short episodes of coughing & $\begin{array}{l}\text { Occasional coughs or rare episodes of } \\
\text { prolonged coughing }\end{array}$ & $\begin{array}{l}\text { Frequent coughs or at least occasional } \\
\text { episodes of prolonged coughing }\end{array}$ \\
\hline Feverishness & No fever or flushed appearance & Felt warm to the touch, no flushing & $\begin{array}{l}\text { Felt very warm to the touch or tempera- } \\
\text { ture }>38.0^{\circ} \mathrm{C} \text {, slightly flushed }\end{array}$ & $\begin{array}{l}\text { Felt hot to the touch or tempera- } \\
\text { ture }>38.8^{\circ} \mathrm{C} \text {, very flushed }\end{array}$ \\
\hline Chillness & No chillness & $\begin{array}{l}\text { Complaining about being cold, no extra } \\
\text { clothing or blankets }\end{array}$ & $\begin{array}{l}\text { Wearing extra clothes or using a blanket } \\
\text { to keep warm }\end{array}$ & $\begin{array}{l}\text { Very chilled, shivering, constantly under } \\
\text { a blanket to keep warm }\end{array}$ \\
\hline Sore throat & No sore throat & Mild pain with swallowing & Moderate pain with swallowing & Very painful to swallow \\
\hline Hoarseness & No change in voice & Speech is slightly hoarse or husky & Speech is very hoarse or husky & $\begin{array}{l}\text { Can't speak above a whisper because or } \\
\text { hoarseness }\end{array}$ \\
\hline
\end{tabular}

Table 1. Questionnaire filled by the caregivers rating the presence and severity of upper respiratory infection (URI) symptoms in children ${ }^{12}$. The Questionnaire was obtained and modified from Taylor et al. Pediatr. Res. 2010 Sep;68(3):252-7.

from 30th November 2017 to 1st February 2019. Patients were excluded if they underwent laparoscopic surgical procedures, were diagnosed with pneumonia or bronchiolitis at the time of surgery, or had a history of prematurity ( $<37$ weeks) or bronchopulmonary dysplasia. In addition, children with high fever (body temperature $>38.8^{\circ} \mathrm{C}$ ), abnormal lung sounds, or aggravated general weakness were excluded, and their surgery was postponed.

Anaesthesia protocol. Intravenous cannulation was performed preoperatively in the ward per our hospital policy. When a patient arrived at an operating room, pulse oximetric readings and the electrocardiogram were monitored, and blood pressure was measured every 2.5-5 min. General anaesthesia was induced with propofol 2-3 $\mathrm{mg} \mathrm{kg}^{-1}$, fentanyl 1-2 $\mathrm{mcg} \mathrm{kg}^{-1}$, and rocuronium $0.6 \mathrm{mg} \mathrm{kg}^{-1}$. Mask ventilation was performed with $6 \mathrm{~L} \mathrm{~min}^{-1}$ of $100 \% \mathrm{O}_{2}$ with $2.5-3$ vol\% of sevoflurane, and tidal volume was adjusted to about $8 \mathrm{~mL} \mathrm{~kg}^{-1}$ with peak inspiratory pressure of less than $15 \mathrm{cmH}_{2} \mathrm{O}$ if possible. Tracheal intubation or supraglottic airway device (SAD) insertion was performed at least $3 \mathrm{~min}$ after rocuronium administration. After securing the airway, $\mathrm{FiO}_{2}$ was reduced to 0.5 and alveolar recruitment was performed by increasing the positive pressure up to $30 \mathrm{cmH}_{2} \mathrm{O}$ step-wise. Initial mechanical ventilation was commenced in the volume-targeted pressure-controlled mode to deliver a tidal volume of $8 \mathrm{~mL} \mathrm{~kg}^{-1}$ at an inspiration:expiration ratio of 1:2 with zero positive-end expiratory pressure. The respiratory rate was adjusted to target an end-tidal carbon dioxide level of 35 to $40 \mathrm{mmHg}$. Anaesthesia was maintained with sevoflurane or desflurane at $0.8-1.0$ minimum alveolar concentration. All anaesthetic management procedures were conducted by a paediatric anaesthesia specialist.

At the end of the surgical procedures, appropriate methods of analgesia were provided depending on surgery, volatile anaesthetic was discontinued, and atropine and neostigmine were administered for the reversal from residual muscle relaxation. Extubation was performed when the patient presented signs of grimace, eye opening, vocalisation, and spontaneous turning of the head. Then the patient was transferred to the post-anaesthesia recovery care unit (PACU), where standard monitoring was applied and vital signs were checked by nurses. The patient was observed for at least $30 \mathrm{~min}$ and discharged from the PACU when the modified Aldrete score was 9 or higher ${ }^{11}$.

Survey of upper respiratory infection symptoms. To evaluate the presence and severity of URI, the 'URI score' was obtained from a modified existing questionnaire ${ }^{12}$ completed by the primary caregiver before anaesthetic induction. This questionnaire assessed $8 \mathrm{URI}$ symptoms and each item is scored from 0 to 3 points; thus, the severity of URI is presented as a sum of the scores, from 0 to 24 points (Table 1). In addition, information on the duration of symptoms, whether any cold medication was taken, parents' smoking history, and the child's history of asthma or allergy were also gathered.

Lung ultrasonography and scoring of atelectasis. Transthoracic pulmonary ultrasonography was performed according to a previously published method $^{3}$, which has been shown to be effective for diagnosing pulmonary atelectasis in children ${ }^{13}$. One designated researcher who was blinded to the child's URI symptoms and experienced with sonographic measurement of atelectasis conducted the sonographic examinations.

Pulmonary ultrasonography was performed twice in each patient. The first examination was conducted within 3 min of starting mechanical ventilation after induction of general anaesthesia. Lung recruitment was performed just after the first sonographic examination. The second examination was conducted at the end of the surgery. The 6-13-MHz linear probe of an ultrasonic device (LOGIQ-e, GE Healthcare, Wauwatosa, WI, USA) was applied vertically to the children's ribs (anterior and lateral) or horizontally between the ribs (posterior), and a 2-dimensional classic view (depth $4 \mathrm{~cm}$ ) was obtained. The segmentation for ultrasonography was divided into six regions per hemi-thorax, and 12 regions were evaluated overall (Fig. 1). 


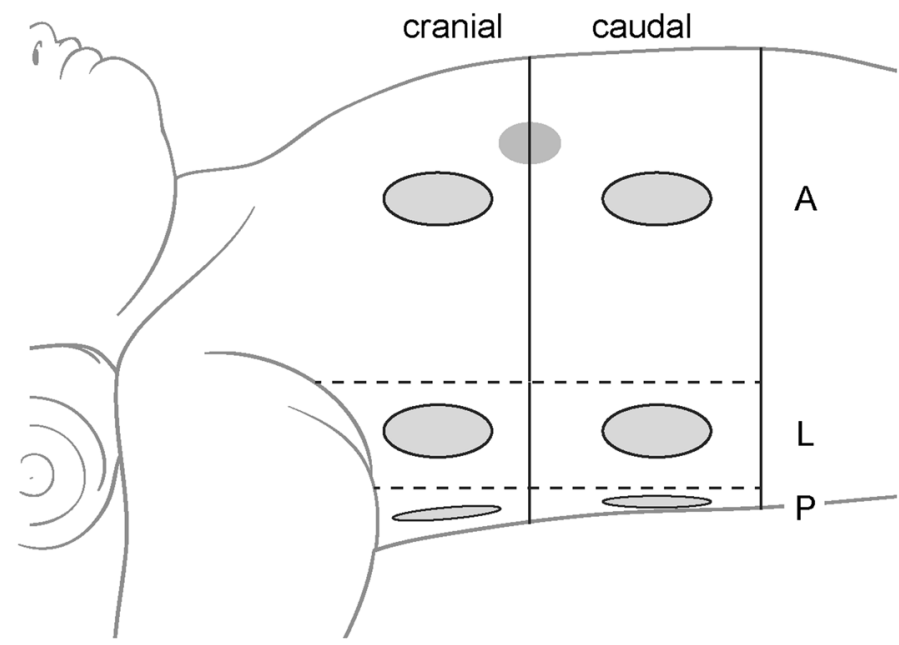

Figure 1. Segmentation of lung ultrasonography. The black axial line divides the thorax into the cranial and caudal regions based on the nipple. The vertical line divides the lung into A: anterior, L: lateral, P: posterior based on the parasternal, anterior, and posterior axillary line.

Atelectasis scoring was based on the findings of juxtapleural consolidation and B-line. The degree of juxtapleural consolidation was divided into four grades and scored between 0 and 3: 0 , no consolidation; 1 , minimal consolidation; 2, small-sized consolidation; and 3, large-sized consolidation. The degree of B-lines was also divided into four grades and scored between 0 and 3: 0, fewer than three isolated B-lines; 1, multiple well-defined B-lines; 2, multiple coalescent B-lines; and 3, white lung ${ }^{3}$. The 'atelectasis score' was presented as the sum of the scores of the 12 areas of consolidation and B-lines, from 0 to 36 , respectively.

During recovery from anaesthesia, the other designated researcher who was blinded to the child's URI symptoms recorded the occurrence of PRAEs, including laryngospasm, bronchospasm, sustained cough, or desaturation events $\left(\mathrm{SpO}_{2}<95 \% \text { on room air in } \mathrm{PACU}\right)^{2}$.

Outcomes. The primary outcome was to define the correlation between URI and atelectasis scores after induction and at the end of the surgery. Secondary outcomes, including the correlation between other patient characteristics and atelectasis scores, were also analysed. In addition, the correlation between URI scores, patient characteristics, and PRAEs were analysed.

Sample size calculation. As this study was an observational study, so any patients aged 6 months to 6 years who underwent general anaesthesia for paediatric general or urologic surgery from 30th November 30, 2017 to 1st February 1, 2019 were eligible in the study, except those who met any of the exclusion criteria.

Statistical analysis. Statistical analysis was performed using SAS (version 9.4, SAS Inc., Cary, NC, USA). For assumption of normal distribution, Shapiro-Wilk test was used. On the basis of the normality of data, continuous variables (age, height, weight, duration of operation, duration of anaesthesia, URI score, URI onset day, and scores for pulmonary atelectasis) were expressed as mean numbers (SD). All categorical and ranking variables (sex, ASA PS [American society of anaesthesiologists physical status], type of surgery, airway device use, URI medication, and history of paternal smoking, asthma, and drug allergy) were expressed as number and percentage (\%).

To determine whether the severity of URI was associated with the atelectasis score, multiple linear regression analysis was performed. The statistical result of this analysis was expressed as coefficient; $B$ and $p$ value. The variables used in the regression analysis were analysed by factors that significantly increased PRAEs in general anaesthesia in children with URI symptoms in a previous study ${ }^{1}$. In the linear regression model, there was multicollinearity between the anaesthesia time and operation time (variance inflation factor $\geq 10$ ), so the anaesthesia time was used for analysis. Missing data were excluded from the analysis.

The factors associated with PRAEs were analysed with univariate logistic regression. Since the number of events $(n=14)$ was too small to be modelled by one-in-ten rule, only univariate logistic regression was used. The results were expressed as odds ratio (OR), 95\% confidence interval (CI), and p values. $P<0.05$ was considered statistically significant.

\section{Results}

Overall, 270 children were enrolled in the study. Of these, nine patients were excluded; three patients' caregivers refused to participate, and elective surgery was postponed in six children due to severe URI symptoms. Of the remaining 261 patients, one patient was lost to follow-up because ultrasonography could not be performed at the end of surgery by the designated researcher due to conflicting schedules with another operation, and four 


\section{CONSORT 2010 Flow Diagram}

\section{Enrolment}

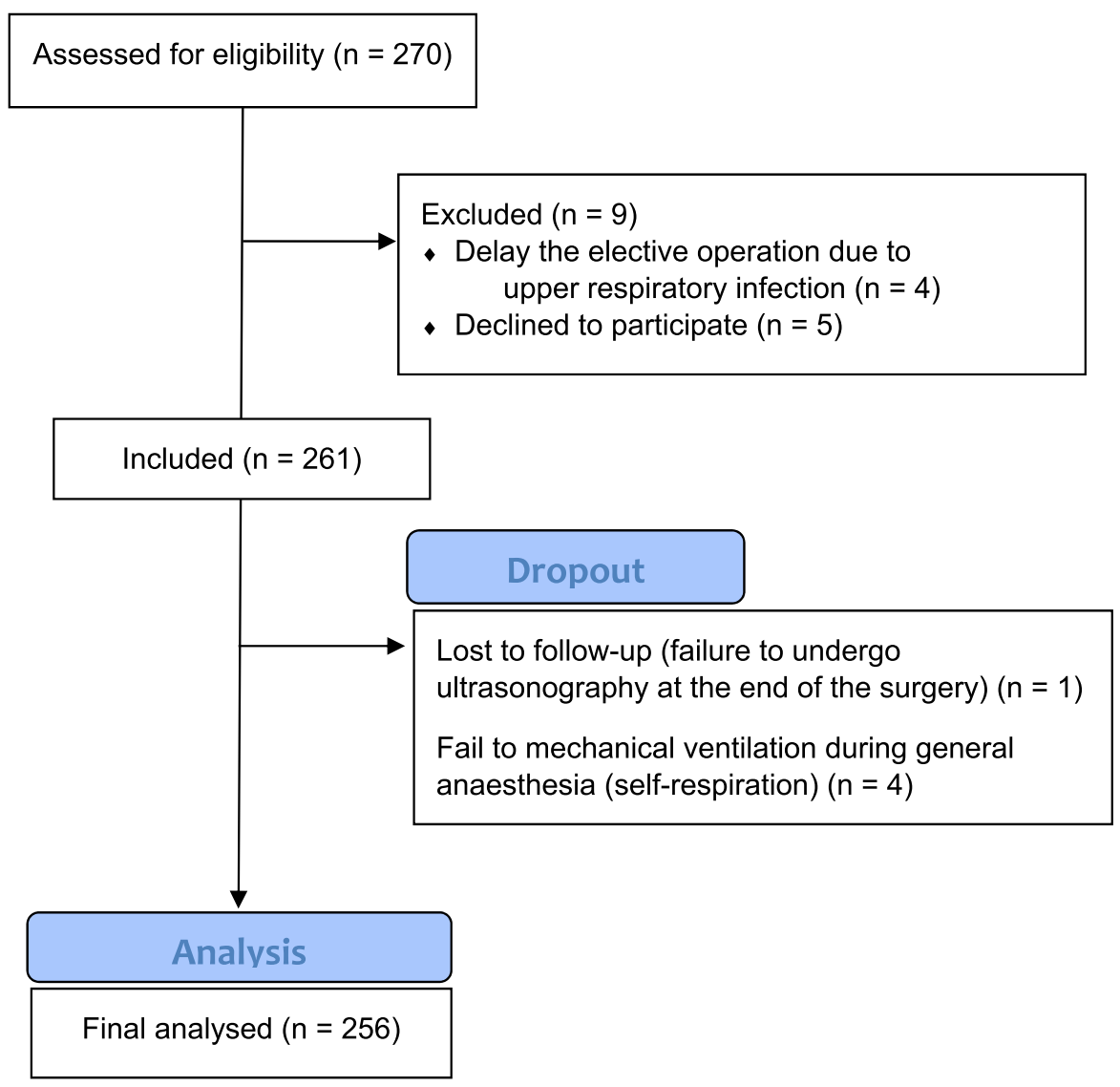

Figure 2. Flow diagram of the study.

children showed restoration of spontaneous respiration before the end of surgery. Therefore, 256 patients were finally analysed (Fig. 2).

Patient characteristics are presented in Table 2. The most common URI symptom was 'runny nose' (37.8\%), and the symptom scores were just 1 or 2 in $49 \%$ of the children with URI.

Primary outcome. In our entire cohort, URI scores did not correlate with the atelectasis scores at both time points (after induction or at the end of surgery) (Table 3). In terms of other URI-related medical history, URI onset day was correlated with the B-line score at the at the end of surgery $(\beta=-0.18, p=0.023)$. The more recent the onset of URI, the worse the degree of B-line at the end of surgery.

Secondary outcome. The age of the patient was associated with the atelectasis scores at both time points; younger children tended to have more B-lines and more consolidation after induction and at the end of surgery. Higher ASA PS was also related to B-lines perioperatively (Table 3 ).

Based on the above findings, we categorised the children into two groups by age: infants $(<12$ months $)$ and toddlers ( $\geq 12$ months). We also divided the children into the following two groups by severity of URI: children with a score of 0 or 1 (no or minimal URI) and those with a score $\geq 2$ (mild or moderate URI). In the URI score $\geq 2$ group, the scores of B-line finding were higher than those in the URI score 0 or 1 group, but only in the toddlers (Table 4 ).

PRAEs occurred in 14 of 261 patients (5.4\%). The numbers of patients with each symptom were as follows; sustained cough, 5; laryngospasm, 4; bronchospasm, 2; $\mathrm{SpO}_{2}<95 \%$ in room air, 2 immediately after emergence and 1 in the PACU. The presence of URI symptoms significantly increased the risk of PRAEs (odds ratios [OR] $7.63,95 \%$ confidence interval $[\mathrm{CI}] 1.67-34.80, \mathrm{p}=0.009)$. Furthermore, children with higher URI scores were more likely to have PRAEs (OR 1.36, 95\% CI 1.10-1.67, $\mathrm{p}=0.004$ ). There were no correlations observed between the occurrence of PRAEs and perioperative sonographic atelectasis findings (Table 5).

Only one child presented with oxygen saturation less than $95 \%$ in room air in the PACU. This child received $5 \mathrm{~L} \mathrm{~min}{ }^{-1}$ of oxygen through a shower tent in the ward. He had been diagnosed with bronchiolitis 7 days prior to surgery and was treated from the onset until the day of surgery. The patient did not have any symptoms other than cough (score 2: occasional coughs, and total URI score was 2) on the day of surgery. Postoperative chest 


\begin{tabular}{|c|c|c|c|}
\hline \multicolumn{2}{|l|}{ Variables } & \multicolumn{2}{|c|}{$\begin{array}{l}\text { Mean (SD), Median (IQR [range]) or n } \\
(\%)\end{array}$} \\
\hline \multicolumn{4}{|l|}{ General characteristics } \\
\hline \multicolumn{2}{|l|}{ Age (month) } & \multicolumn{2}{|c|}{$16.0(9.0-32.0[6.0-72.0])$} \\
\hline \multicolumn{2}{|l|}{ Weight (Kg) } & \multicolumn{2}{|c|}{$10.8(9.2-13.7[6.0-27.0])$} \\
\hline \multicolumn{2}{|l|}{ Height $(\mathrm{cm})$} & \multicolumn{2}{|c|}{79.1 (70.8-91.1 [51.0-117.5]) } \\
\hline \multicolumn{2}{|l|}{$\operatorname{Sex}(M / F)$} & \multicolumn{2}{|c|}{$233(91.0) / 23(9.0)$} \\
\hline \multicolumn{2}{|c|}{ Surgery (General/Urologic) } & \multicolumn{2}{|c|}{$38(14.8) / 218(85.2)$} \\
\hline \multirow{3}{*}{ General } & Herniorrhaphy & \multicolumn{2}{|l|}{$21(8.2)$} \\
\hline & Epidermal cyst excision & \multicolumn{2}{|l|}{$14(5.5)$} \\
\hline & Sistrunk operation & \multicolumn{2}{|l|}{$3(1.2)$} \\
\hline \multirow{4}{*}{ Urologic } & Herniorrhaphy & \multicolumn{2}{|l|}{$71(27.7)$} \\
\hline & \begin{tabular}{|l|} 
Orchiopexy \\
\end{tabular} & \multicolumn{2}{|l|}{$67(26.2)$} \\
\hline & Penoplasty & \multicolumn{2}{|l|}{$45(17.6)$} \\
\hline & Repair of hypospadias & \multicolumn{2}{|l|}{$35(13.7)$} \\
\hline \multicolumn{2}{|c|}{ Airway device (SAD/intubation) } & \multicolumn{2}{|c|}{$221(86.3) / 35(13.7)$} \\
\hline \multicolumn{2}{|l|}{ ASA PS $(1 / 2 / 3)$} & \multicolumn{2}{|c|}{$154(60.2) / 101(39.5) / 1(0.4)$} \\
\hline \multicolumn{2}{|l|}{ Operation time ( $\mathrm{min})$} & \multicolumn{2}{|l|}{$46.3(34.4)$} \\
\hline \multicolumn{2}{|l|}{ Anaesthesia time (min) } & \multicolumn{2}{|l|}{$75.0(36.9)$} \\
\hline \multicolumn{4}{|l|}{ URI-related information } \\
\hline & No $(n, \%)$ & Yes $(n, \%)$ \\
\hline \multicolumn{2}{|l|}{ URI symptom } & $137(53.5)$ & 119 (46.5) \\
\hline URI score $^{\mathrm{a}}$ & & $\mathrm{n} / \mathrm{a}$ & $1.4(2.0)$ \\
\hline URI onset day (day) ${ }^{\mathrm{b}}$ & & $\mathrm{n} / \mathrm{a}$ & $3.0(5.0)$ \\
\hline URI medication & & $184(71.9)$ & $72(28.1)$ \\
\hline Other medical/parental & & & \\
\hline & & No $(n, \%)$ & Yes $(n, \%)$ \\
\hline Parental smoking & & $188(73.4)$ & $68(26.6)$ \\
\hline Asthma history & & $255(99.6)$ & $1(0.4)$ \\
\hline Allergic history & & $255(99.6)$ & $1(0.4)$ \\
\hline
\end{tabular}

Table 2. Characteristics of children included in the present study. Values are presented as mean (SD), median (IQR [range]) and n (\%). M; male, F; female, SAD; supraglottic airway device, ASA PS; American society of

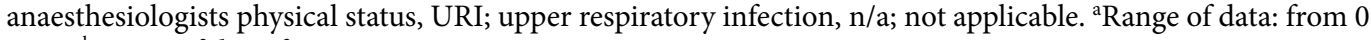
to 24 . ${ }^{\text {R }}$ ange of data: from 0 to 20 .

radiography showed subsegmental atelectasis in the right lower lobe. He recovered spontaneously the next day and was discharged.

\section{Discussion}

In this prospective observational study, we assessed the correlation between the severity of URI symptoms and anaesthesia-induced atelectasis measured by ultrasonography in children aged 6 months to 6 years. Across the entire age cohort, mild URI was not related to aggravation of anaesthesia-induced atelectasis.

We found no correlation between URI score and atelectasis score in young children overall. One possible explanation for this finding is that the distribution of severity of URI was neither even nor wide; the mean score was 1.43 , and the maximum score in this study was only 9 points out of a possible 24 . In actual clinical situations, children with higher URI scores are rarely seen in the operating room because elective surgery is postponed if a child has severe URI symptoms. A number of children in our study population presented with higher URI scores and their procedure was rescheduled. Therefore, the patients in this study seem to accurately reflect the actual population of children that we face in the operating room, and we can postulate that minimal or mild URI symptoms are less likely to aggravate perioperative atelectasis to a clinically significant level.

Meanwhile, regardless of the symptoms of URI, there was a clear association between age and atelectasis. We had already excluded babies younger than 6 months because of the greater incidence of perioperative atelectasis in younger children ${ }^{3,14}$, which could obscure any effects of URI. Nevertheless, age remained significantly related to the severity of atelectasis in our result, and younger children were more prone to development of atelectasis after anaesthesia induction as well as at the end of surgery. Accordingly, strategies to reduce atelectasis should be considered and applied for infants and younger toddlers during both induction and maintenance of anaesthesia.

We categorised the children into the following two groups: children with a score of 0 or 1 (no or minimal $\mathrm{URI}$ ) and those with a score $\geq 2$ (mild or moderate URI). In toddlers, the B-lines were significantly more severe in the URI score $\geq 2$ group than in the URI score of 0 or 1 group, both after induction and at the end of surgery. B-lines are vertically oriented artefacts which indicate an abnormality in the interstitial or alveolar compartment and can be used to estimate the extent of the altered lung parenchyma, whether it is from extravascular water 


\begin{tabular}{|c|c|c|c|c|c|c|c|c|}
\hline \multirow[b]{3}{*}{ Variables } & \multicolumn{4}{|c|}{ After induction } & \multicolumn{4}{|c|}{ At the end of surgery } \\
\hline & \multicolumn{2}{|c|}{ Consolidation } & \multicolumn{2}{|l|}{ B-line } & \multicolumn{2}{|c|}{ Consolidation } & \multicolumn{2}{|l|}{ B-line } \\
\hline & $\beta$ & p value & $\beta$ & p value & $\beta$ & p value & $\beta$ & p value \\
\hline \multicolumn{9}{|l|}{ URI-related } \\
\hline URI score $^{\mathrm{a}}$ & 0.13 & 0.31 & 0.31 & 0.098 & -0.04 & 0.762 & 0.23 & 0.223 \\
\hline URI onset day ${ }^{\mathrm{b}}$ & 0.00 & 0.987 & -0.15 & 0.053 & -0.07 & 0.219 & -0.18 & $\underline{0.023}$ \\
\hline URI medication ( $\mathrm{N}$ vs. $\mathrm{Y}$ ) & -0.12 & 0.858 & 1.22 & 0.184 & 0.71 & 0.292 & 1.37 & 0.147 \\
\hline \multicolumn{9}{|l|}{ General characteristics } \\
\hline Age & -0.09 & $\leq .0001$ & -0.12 & $\leq .0001$ & -0.07 & $\underline{0.001}$ & -0.08 & $\underline{0.005}$ \\
\hline Weight & 0.14 & $\underline{0.003}$ & 0.06 & 0.377 & 0.14 & $\underline{0.006}$ & 0.13 & 0.056 \\
\hline Height & -0.02 & 0.373 & 0.00 & 0.95 & -0.04 & 0.124 & -0.02 & 0.626 \\
\hline $\operatorname{Sex}(\mathrm{F} v s . \mathrm{M})$ & 0.36 & 0.59 & 1.30 & 0.168 & -0.35 & 0.609 & 0.81 & 0.403 \\
\hline Surgery (GS vs. urologic) & -0.79 & 0.153 & 0.12 & 0.881 & 0.20 & 0.729 & -0.10 & 0.901 \\
\hline Airway (SAD vs. intubation) & 0.01 & 0.991 & -0.46 & 0.617 & -0.58 & 0.40 & -0.75 & 0.436 \\
\hline ASA PS $(1 v s .2)$ & 0.75 & 0.064 & 1.55 & $\underline{0.006}$ & 0.07 & 0.876 & 1.81 & $\underline{0.002}$ \\
\hline (1 vs. 3) & 2.68 & 0.336 & 7.11 & 0.069 & 1.56 & 0.585 & 4.28 & 0.29 \\
\hline Anaesthesia time & -0.01 & 0.265 & 0.00 & 0.912 & -0.00 & 0.836 & 0.01 & 0.474 \\
\hline \multicolumn{9}{|l|}{ Parental information } \\
\hline Parental smoking ( $\mathrm{N}$ vs. $\mathrm{Y}$ ) & -0.10 & 0.806 & 0.44 & 0.457 & -0.52 & 0.238 & 0.39 & 0.526 \\
\hline
\end{tabular}

Table 3. Multivariable analysis of factors associated with the atelectasis score measured at the post-induction and before-emergence periods using transthoracic lung ultrasonography. Values are presented as coefficient; $\beta$ and $p$ value. URI; upper respiratory infection, $N$; no, Y; yes, $F$; female, $M$; male, GS; general surgery, SAD; supraglottic airway device, ASA PS; American society of anaesthesiologists physical status. ${ }^{\text {Renange of data: }}$

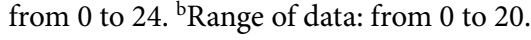

\begin{tabular}{|c|c|c|c|c|c|}
\hline Sonographic finding & & URI score $<2$ & URI score $\geq 2$ & \begin{tabular}{|l} 
Difference \\
$(95 \%$ CI $)$
\end{tabular} & p value \\
\hline & \multicolumn{5}{|l|}{ After induction } \\
\hline \multirow{3}{*}{ B-line } & All age & $7.98(4.13)$ & $9.18(4.39)$ & $1.20(0.11-2.30)$ & $\underline{0.031}$ \\
\hline & $<12$ months & $10.08(3.58)$ & $11.36(4.53)$ & $1.28(-0.54-3.10)$ & 0.172 \\
\hline & $\geq 12$ months & $6.70(3.93)$ & $8.33(4.06)$ & $1.63(0.38-2.87)$ & $\underline{0.013}$ \\
\hline \multirow{4}{*}{ Consolidation } & All age & $3.09(2.87)$ & $3.66(3.06)$ & $0.57(-0.19-1.33)$ & 0.142 \\
\hline & $<12$ months & $4.30(3.10)$ & $4.64(2.91)$ & $0.34(-1.10-1.77)$ & 0.641 \\
\hline & $\geq 12$ months & $2.36(2.47)$ & $3.28(3.05)$ & $0.93(0.78-1.77)$ & $\underline{0.028}$ \\
\hline & \multicolumn{5}{|c|}{ At the end of the surgery } \\
\hline \multirow{3}{*}{ B-line } & All age & $8.79(4.20)$ & $9.71(4.54)$ & $0.92(-0.20-2.03)$ & 0.114 \\
\hline & $<12$ months & $10.49(4.16)$ & $10.60(4.49)$ & $0.11(-1.90-2.11)$ & 0.923 \\
\hline & $\geq 12$ months & $7.76(3.89)$ & $9.36(4.54)$ & $1.60(0.30-2.90)$ & $\underline{0.021}$ \\
\hline \multirow{3}{*}{ Consolidation } & All age & $3.50(3.03)$ & $3.57(2.86)$ & $0.07(-0.70-0.83)$ & 0.863 \\
\hline & $<12$ months & $5.00(3.34)$ & $4.84(2.61)$ & $-0.16(-1.64-1.32)$ & 0.834 \\
\hline & $\geq 12$ months & $2.60(2.42)$ & $3.08(2.81)$ & $0.48(-0.33-1.29)$ & 0.241 \\
\hline
\end{tabular}

Table 4. Atelectasis scores (B-line, Consolidation) according to patient's age after induction and at the end of the surgery periods; URI score $<2$ (no or minimal URI) $v s . \geq 2$ (mild or moderate URI). Values are presented as mean (SD) and mean difference (95\% confidence interval). CI; confidence interval, URI; upper respiratory infection.

or inflammation ${ }^{13}$. The number of B-lines correlates with the extent of parenchymal changes on $\mathrm{CT}^{9}$. This result can be interpreted that mild current URI have some detrimental effect such as minor atelectasis or infection/ inflammation on lower respiratory tracts, and general anaesthesia does not seem to aggravate it.

von Ungern-Sternberg noted that present or recent URI is associated with an increased risk for PRAEs, but the analysis in that study did not consider the severity of $\mathrm{URI}^{2}$. Another research group developed the COLDS score, which assesses the current signs and symptoms, onset of symptoms, presence of lung disease, airway devices, and surgery, and showed that higher COLDS scores possibly predict PRAEs ${ }^{15}$. However, Lee's study did not reveal that how each factor would contribute to the occurrence of PRAEs, and the severity of symptoms was categorized as none, mild, and moderate/severe. Our study showed that the incidence of PRAEs was significantly higher in children with only mild symptoms of URI and that severity differences in even mild URI could influence PRAEs. 


\begin{tabular}{|c|c|c|c|}
\hline & & OR (95\% CI) & p value \\
\hline \multicolumn{4}{|l|}{ URI-related } \\
\hline URI symptom & no vs. yes & $7.63(1.67-34.8)$ & $\underline{0.009}$ \\
\hline \multicolumn{2}{|l|}{ URI score ${ }^{\mathrm{a}}$} & $1.36(1.10-1.67)$ & $\underline{0.004}$ \\
\hline \multicolumn{2}{|l|}{ URI onset day ${ }^{\mathrm{b}}$} & $1.05(0.97-1.14)$ & 0.253 \\
\hline URI medication & no $v s$. yes & $2.68(0.91-7.94)$ & 0.075 \\
\hline \multicolumn{4}{|c|}{ Ultrasonographic finding } \\
\hline \multirow{2}{*}{ After induction } & consolidation & $1.14(0.97-1.35)$ & 0.118 \\
\hline & B-line & $1.05(0.92-1.20)$ & 0.462 \\
\hline \multirow{2}{*}{ At the end of surgery } & consolidation & $1.16(0.99-1.36)$ & 0.060 \\
\hline & B-line & $1.12(0.99-1.26)$ & 0.074 \\
\hline \multicolumn{4}{|l|}{ General characteristics } \\
\hline \multicolumn{2}{|l|}{ Age (month) } & $1.00(0.97-1.03)$ & 0.957 \\
\hline \multicolumn{2}{|l|}{ Weight (kg) } & $1.00(0.89-1.12)$ & 0.978 \\
\hline \multicolumn{2}{|l|}{ Height $(\mathrm{cm})$} & $1.01(0.97-1.06)$ & 0.531 \\
\hline Sex & F vs. M & $0.54(0.11-2.57)$ & 0.438 \\
\hline Surgery & GS vs. Urologic & $0.41(0.12-1.37)$ & 0.147 \\
\hline Airway device & SAD vs. intubation & $0.47(0.06-3.73)$ & 0.477 \\
\hline \multirow[t]{2}{*}{ ASA PS } & $1 v s .2$ & $1.16(0.40-3.34)$ & 0.782 \\
\hline & 1 vs.3 & $5.7(0.06-560.20)$ & 0.457 \\
\hline \multicolumn{2}{|l|}{ Operation time } & $0.99(0.97-1.01)$ & 0.425 \\
\hline \multicolumn{2}{|l|}{ Anaesthetic time } & $0.99(0.97-1.01)$ & 0.336 \\
\hline \multicolumn{4}{|l|}{ Parental information } \\
\hline Parental smoking & no $v s$. yes & $1.14(0.35-3.77)$ & 0.827 \\
\hline
\end{tabular}

Table 5. Univariate analysis of risk factors for perioperative respiratory adverse events. Values are presented as the odds ratio (95\% confidential interval). OR; odds ratio, CI; confidence interval, URI; upper respiratory infection, F; female, M; male, GS; general surgery, SAD; supraglottic airway device, ASA PS; American society of anaesthesiologists physical status. ${ }^{\mathrm{a}}$ Range of data: from 0 to 24 . ${ }^{\mathrm{b}}$ Range of data: from 0 to 20 .

Diagnosis of atelectasis using lung ultrasound has been widely used recently. It can be easily applied to patients in the operating room and is free of radiation exposure. Moreover, the sensitivity of atelectasis diagnosis is as high as $88 \%{ }^{13}$. Ultrasonographic findings are known to highly correlate with the atelectasis volume measured on computed tomography $(\mathrm{CT})^{16}$, and CT yields more accurate diagnoses of atelectasis than chest radiographs ${ }^{17}$. However, clinically significant differences in atelectasis scores using sonography have not been evaluated. Song et al. scanned the same lesions we did and obtained atelectasis scores, but they defined anaesthesia-induced atelectasis to be significant if any region had a consolidation score of $\geq 2$. Another author adopted a completely different scoring system to compare sonographic findings of atelectasis ${ }^{4}$. Therefore, a consensus on the criteria in terms of clinically meaningful scores or findings needs to be established.

There are several limitations of this study. First, any surgical procedures that may affect pulmonary function were excluded; accordingly, children undergoing urologic or lower abdominal procedures were recruited, and the proportion of male children was higher. Second, the validity of the URI scoring system in this population could be questioned. It was introduced by Tailor et al. in 2010 for use in clinical studies to differentiate children with cold symptoms and was based on children aged $2-10$ years. According to the authors, its sensitivity is $81.4 \%$, specificity is $61.9 \%$, and accuracy is $73.3 \%{ }^{12}$. It is the only objective scoring system available. However, the children enrolled in our study were 6 months to 6 years of age and were generally younger than the children in the original study. Third, airway devices were chosen as routinely used, and SADs were used in more than $85 \%$ of the children; accordingly, some cases did not reach the pressure of $30 \mathrm{cmH}_{2} \mathrm{O}$ because sealing pressure was below $30 \mathrm{cmH}_{2} \mathrm{O}$, leading to the probability of incomplete alveolar recruitment. Nevertheless, the use of SADs was not associated with atelectasis in comparison with intubation in the result, and rather reduced the incidence of PRAEs, which was only $5.4 \%$ in this study.

In conclusion, children who received anaesthesia in the operating room often had mild URI symptoms, which did not aggravate anaesthesia-induced atelectasis. However, the results of this study emphasised that the risk of PRAEs should always be considered during anaesthetic care of children with even mild URI, and the risk is correlated with the severity of PRAEs.

Received: 27 July 2020; Accepted: 26 February 2021

Published online: 16 March 2021

\section{References}

1. Tait, A. R. et al. Risk factors for perioperative adverse respiratory events in children with upper respiratory tract infections. Anesthesiology 95, 299-306 (2001). 
2. von Ungern-Sternberg, B. S. et al. Risk assessment for respiratory complications in paediatric anaesthesia: a prospective cohort study. Lancet (London, England) 376, 773-783. https://doi.org/10.1016/s0140-6736(10)61193-2 (2010).

3. Song, I. K. et al. Effects of an alveolar recruitment manoeuvre guided by lung ultrasound on anaesthesia-induced atelectasis in infants: a randomised, controlled trial. Anaesthesia 72, 214-222. https://doi.org/10.1111/anae.13713 (2017).

4. Acosta, C. M. et al. Lung recruitment prevents collapse during laparoscopy in children: a randomised controlled trial. Eur. J. Anaesthesiol 35, 573-580. https://doi.org/10.1097/eja.0000000000000761 (2018).

5. Williams, O. A., Hills, R. \& Goddard, J. M. Pulmonary collapse during anaesthesia in children with respiratory tract symptoms. Anaesthesia 47, 411-413 (1992).

6. McGill, W. A., Coveler, L. A. \& Epstein, B. S. Subacute upper respiratory infection in small children. Anesth. Analg. 58, 331-333. https://doi.org/10.1213/00000539-197907000-00017 (1979).

7. DeSoto, H., Patel, R. I., Soliman, I. E. \& Hannallah, R. S. Changes in oxygen saturation following general anesthesia in children with upper respiratory infection signs and symptoms undergoing otolaryngological procedures. Anesthesiology 68, 276-279. https ://doi.org/10.1097/00000542-198802000-00017 (1988).

8. Taguchi, N., Matsumiya, N., Ishizawa, Y., Dohi, S. \& Naito, H. The relation between upper respiratory tract infection and mild hypoxemia during general anesthesia in children. Masui. Jpn. J. Anesthesiol. 41, 251-254 (1992).

9. Martelius, L., Heldt, H. \& Lauerma, K. B-lines on pediatric lung sonography: comparison with computed tomography. J. Ultrasound Med. 35, 153-157. https://doi.org/10.7863/ultra.15.01092 (2016).

10. Cate, T. R., Roberts, J. S., Russ, M. A. \& Pierce, J. A. Effects of common colds on pulmonary function. Am. Rev. Resp. Dis. 108, 858-865. https://doi.org/10.1164/arrd.1973.108.4.858 (1973).

11. Aldrete, J. A. The post-anesthesia recovery score revisited. J. Clin. Anesth. 7, 89-91. https://doi.org/10.1016/0952-8180(94)00001 $-k(1995)$.

12. Taylor, J. A., Weber, W. J., Martin, E. T., McCarty, R. L. \& Englund, J. A. Development of a symptom score for clinical studies to identify children with a documented viral upper respiratory tract infection. Pediatr. Res. 68, 252-257. https://doi.org/10.1203/00006 450-201011001-0049310.1203/PDR.0b013e3181e9f3a0 (2010).

13. Acosta, C. M. et al. Accuracy of transthoracic lung ultrasound for diagnosing anesthesia-induced atelectasis in children. Anesthesiology 120, 1370-1379. https://doi.org/10.1097/aln.0000000000000231 (2014).

14. Serafini, G. et al. Pulmonary atelectasis during paediatric anaesthesia: CT scan evaluation and effect of positive endexpiratory pressure (PEEP). Paediatr. Anaesth. 9, 225-228 (1999).

15. Lee, L. K., Bernardo, M. K. L., Grogan, T. R., Elashoff, D. A. \& Ren, W. H. P. Perioperative respiratory adverse event risk assessment in children with upper respiratory tract infection: Validation of the COLDS score. Paediatr. Anaesth. 28, 1007-1014. https://doi. org/10.1111/pan.13491 (2018).

16. Yu, X. et al. Performance of Lung Ultrasound in Detecting Peri-Operative Atelectasis after General Anesthesia. Ultrasound. Med. Biol. 42, 2775-2784. https://doi.org/10.1016/jultrasmedbio.2016.06.010 (2016).

17. Cantinotti, M. et al. Lung ultrasound reclassification of chest X-ray data after pediatric cardiac surgery. Paediatr. Anaesth. 28, 421-427. https://doi.org/10.1111/pan.13360 (2018).

\section{Acknowledgements}

The authors thank Medical Illustration \& Design, part of the Medical Research Support Services of Yonsei University College of Medicine, for all artistic support related to this work.

\section{Author contributions}

H.M.L conceptualized and designed the study, performed data collection, data analysis, and drafted the manuscript. H.J.B. helped conceive, collected the data, and revised the manuscript. N.K. performed data analysis and revised the manuscript. S.J.G. performed data analysis and revised the manuscript. R.P.F. performed data analysis and revised the manuscript. J.R.L conceptualized and designed study, revised the manuscript. All authors revised and approved the final version of the manuscript.

\section{Competing interests}

The authors declare no competing interests.

\section{Additional information}

Correspondence and requests for materials should be addressed to J.-R.L.

Reprints and permissions information is available at www.nature.com/reprints.

Publisher's note Springer Nature remains neutral with regard to jurisdictional claims in published maps and institutional affiliations.

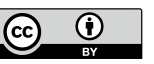

Open Access This article is licensed under a Creative Commons Attribution 4.0 International License, which permits use, sharing, adaptation, distribution and reproduction in any medium or format, as long as you give appropriate credit to the original author(s) and the source, provide a link to the Creative Commons licence, and indicate if changes were made. The images or other third party material in this article are included in the article's Creative Commons licence, unless indicated otherwise in a credit line to the material. If material is not included in the article's Creative Commons licence and your intended use is not permitted by statutory regulation or exceeds the permitted use, you will need to obtain permission directly from the copyright holder. To view a copy of this licence, visit http://creativecommons.org/licenses/by/4.0/.

(C) The Author(s) 2021 